\title{
Fe-Based Nano-Structured Powder Reinforced Zr-Based Bulk Metallic Glass Composites by Powder Consolidation
}

\author{
Seung Mok Cho, Jun Hyun Han, Jin Kyu Lee* and Yu Chan Kim ${ }^{\dagger}$ \\ Division of Materials Science and Engineering, Korea Institute of Science and Technology, P.O.Box 131, \\ Cheongryang, Seoul 130-650, Korea \\ *Division of Advanced Materials Engineering, Kongju National University, 275, Budae-dong, Cheonan, \\ Chungnam, 330-717, Korea
}

(Received August 7, 2009 : Received in revised form September 15, 2009 : Accepted September 16, 2009)

\begin{abstract}
The Zr-based bulk metallic glass matrix composites of a mixture of gas-atomized metallic glass powders and Fe-based nanostructured powders were fabricated by spark plasma sintering. The Fe-based nanostructured powders adopted for the enhancement of plasticity were well distributed in the matrix after consolidation, and the matrix remains as a fully amorphous phase. The successful consolidation of metallic glass matrix composite with high density was attributed to viscous flow in the supercooled liquid state during spark plasma sintering. Unlike other amorphous matrix composites, in which improved ductility could be obtained at the expense of their strength, the developed composite exhibited improvement both in strength and ductility. The ductility improvement in the composite was considered to be due to the formation of multiple shear bands under the presence of the Fe-based nanostructured particles.
\end{abstract}

Key words metallic glass, nano-structure powder, powder metallurgy, spark plasma sintering, mechanical properties, thermal analysis.

\section{Introduction}

Bulk metallic glasses (BMGs) have shown superior properties such as high strength, high wear resistance, low Young's modulus and large elastic limit. ${ }^{1)}$ However, metallic glasses still have some intrinsic disadvantages which restrict their wider commercial applications.

One of the major drawbacks of BMGs is their low plasticity at room temperature, which limits their application as structural materials. Due to the absence of strain hardening, BMGs usually show a catastrophic fracture under mechanical loading, ${ }^{2)}$ and the ductility of most of the BMGs is very limited. ${ }^{3)}$ One way to reduce the brittleness of BMGs is to produce a composite microstructure, consisting of a crystalline phase embedded in an amorphous matrix. The role of the crystalline phase dispersed uniformly in the amorphous matrix is to act as an obstacle to sudden propagation of the shear band, leading to the formation of a large number of shear bands throughout the specimen, and thereby enhancing plasticity. ${ }^{4-6)}$

These amorphous matrix composites can be obtained in

${ }^{\dagger}$ Corresponding author

E-Mail : chany@kist.re.kr (Y. C. Kim) various ways, including partial devitrification of as-cast metallic glasses, mechanical alloying of elemental powders blended with insoluble particles, adding particle or fibers during casting or consolidation process and precipitation of a dendritic crystalline phase during casting. ${ }^{7-12)}$ Many publications have described the successful increase of plastic deformation, but which was decreased in the strength and/or maximum diameter for fully amorphous matrix., ${ }^{72}$

Another drawback which confined application of BMGs is the restriction of the critical size. Since metallic glass is thermodynamically unstable phase, a sufficiently high cooling rate is always required during casting in order to prevent the formation of the more stable crystalline phases. Unfortunately, BMGs produced by casting have been usually limited to size and shape due to the minimum coolingrate required for supercooling without undergoing devitrification until now. Large-scale BMGs have been produced by consolidation process of metallic glass powders using the significant viscous flow in the supercooled liquid region, ${ }^{13-15)}$ such as extrusion or sintering techniques, has attracted growing interest ${ }^{15-21)}$ for the production of bulk metallic glasses with large dimensions and complex shapes.

In this study, we intended to fabricate the large sized BMG matrix composite with improved ductility by adding 
nanostructured Fe-based powder in Zr-based metallic glass powder using spark plasma sintering which is a highly effective method of densifying hard-to-sinter materials in very short time. ${ }^{22)}$ The thermal and deformation behaviors of the resulting MGMCs were investigated.

\section{Experimental Procedures}

$\mathrm{Zr}_{62} \mathrm{Al}_{8} \mathrm{Ni}_{13} \mathrm{Cu}_{17}$ metallic glass powder was fabricated by the high pressure gas atomization process by re-melting the master alloy in a vacuum radio-active furnace of the atomizer $200 \mathrm{~K}$ above the liquidus temperature down to $7.58 \times 10^{-3} \mathrm{~Pa}$, followed by bottom-pouring. An annular Ar gas atomizer was operated at a pressure of $5 \mathrm{MPa}$, and the melt flow rate, as estimated from operating time and weight of atomized melt, was about $1.5 \mathrm{~kg} / \mathrm{min}$. The ironbased nano-structured alloy, e.g. $\mathrm{Fe}_{84.9} \mathrm{Si}_{9.5} \mathrm{Al}_{5.6}$ powder known as Sendust, was prepared by the pulverization of the ribbon; thereby they had irregular shape and rough surfaces. To produce the MGMCs containing a nanostructured $\mathrm{Fe}_{84.9} \mathrm{Si}_{9.5} \mathrm{Al}_{5.6}$ powder powder, metallic glass powder and Fe-based nano-structured powders having a size smaller than $90 \mu \mathrm{m}$ were uniformly blended with a volume fraction of $20 \%$. Besides the composite sample containing $20 \mathrm{Vol} \%$ Fe-based nano-structured powder, and a monolithic BMG sample was prepared for comparison. The mixed powders were pre-compacted, and then consolidated to form disc-shape samples with $12 \mathrm{~mm}$ in diameter and $5 \mathrm{~mm}$ in thickness using a spark plasma sintering (SPS) method. The consolidation processes were performed in the supercooled liquid region of metallic glass powders with an external pressure $300 \mathrm{MPa}$. The time and temperature for consolidation were fixed by changing of Z-position during processing. Structural characterization was performed by X-ray diffractometry (XRD) with $\mathrm{Cu} \mathrm{K} \mathrm{K}_{\alpha}$ radiation and scanning electron microscopy (SEM). Thermal properties of the samples were studied by differential scanning calorimetry (DSC). Mechanical properties of the samples were measured at room temperature under compressive mode with a strain rate of $1 \times 10^{-4} \mathrm{~s}^{-1}$. The specimens with a dimension of $2(\mathrm{w}) \times$ $2(1) \times 4(t) \mathrm{mm}^{3}$ were prepared for compression tests. The interface between the metallic glass matrix and reinforcement was analyzed using transmission electron microscopy (TEM; Philips Tachnai $\mathrm{G}^{2}$ ). Thin foils for TEM were prepared by an ion milling method (Gatan, Model 600).

\section{Results and Discussion}

Fig. 1(a) and (b) show the typical SEM micrograph of the $\mathrm{Zr}_{62} \mathrm{Al}_{8} \mathrm{Ni}_{13} \mathrm{Cu}_{17}$ powder fabricated by gas atomization and the Fe-based nano-structured powder fabricated by pulverization of the ribbon. As shown Fig. 1(a) and (b), spherical morphology as well as clean surfaces was observed in $\mathrm{Zr}_{62} \mathrm{Al}_{8} \mathrm{Ni}_{13} \mathrm{Cu}_{17}$ powder, while irregular shape and rough surfaces was observed in Fe-based nanostructured powder.

Fig. 2(a) and (b) show the typical DSC and XRD curves of the $\mathrm{Zr}_{62} \mathrm{Al}_{8} \mathrm{Ni}_{13} \mathrm{Cu}_{17}$ powder fabricated by gas atomization and the Fe-based nano-structured powder fabricated by pulverization of the ribbon. The XRD pattern obtained from the $\mathrm{Zr}_{62} \mathrm{Al}_{8} \mathrm{Ni}_{13} \mathrm{Cu}_{17}$ powder showed a broad halo peak, indicating the amorphous phase and the XRD pattern obtained from the Fe-based powder showed a shape peak indicated crystalline phase. The DSC trace exhibits one endothermic event, characteristic of the glass transition to a supercooled liquid state, followed by exothermic reaction associated with the crystallization of the supercooled liquid. The glass transition temperature $\left(\mathrm{T}_{\mathrm{g}}\right)$, the crystallization onset temperature $\left(\mathrm{T}_{\mathrm{x}}\right)$ and the crystallization enthalpy $(\Delta \mathrm{H})$ were $660 \mathrm{~K}, 738 \mathrm{~K}$ and $51.3 \mathrm{~J} / \mathrm{g}$, respectively.

Fig. 3(a) (b) show a typical appearance and the morphology of the polished cross section obtained from the consolidated $\mathrm{Zr}_{62} \mathrm{Al}_{8} \mathrm{Ni}_{13} \mathrm{Cu}_{17}$ composite containing $20 \mathrm{Vol} \%$ Fe-based nano-structured powder sample. The Fe-based nano-structured powders were distributed relatively homo-

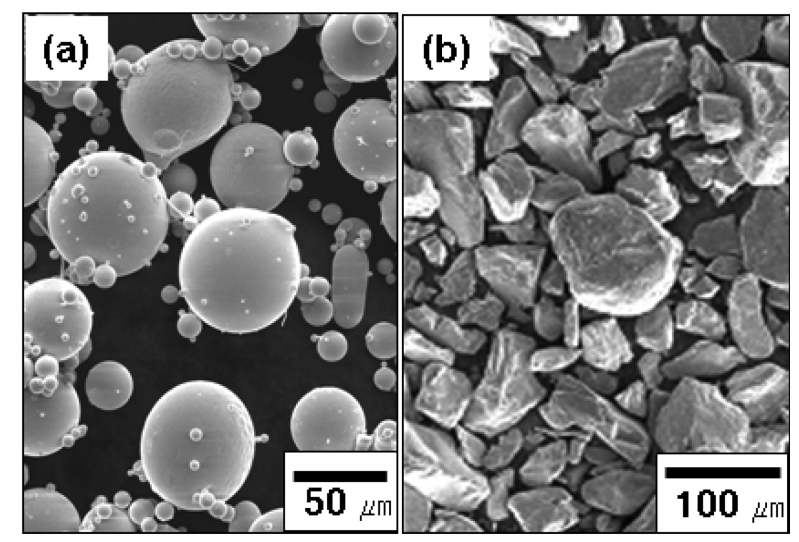

Fig. 1. (a) The typical SEM micrograph of gas atomized $\mathrm{Zr}_{62} \mathrm{Al}_{8} \mathrm{Ni}_{13} \mathrm{Cu}_{17}$ powder, (b) the typical SEM micrograph of the Fe-based nano-structured powder pulverized from the ribbon and (c) DSC and XRD curves of gas atomized $\mathrm{Zr}_{62} \mathrm{Al}_{8} \mathrm{Ni}_{13} \mathrm{Cu}_{17}$ powder. 

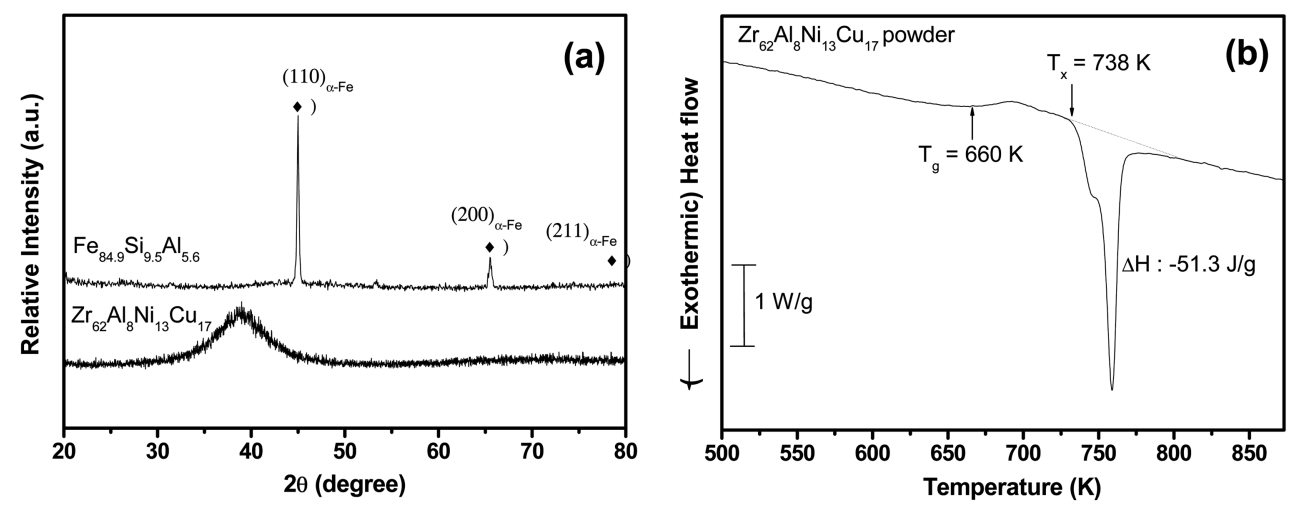

Fig. 2. (a) DSC and (b) XRD curves of gas atomized $\mathrm{Zr}_{62} \mathrm{Al}_{8} \mathrm{Ni}_{13} \mathrm{Cu}_{17}$ powder.

geneously in the metallic glasses matrix. No defect such as pores and cavities was observed at the interface between the Fe-based nano-structured powder and the metallic glass matrix, suggesting that the SPS process causes a severe viscous flow of the metallic glass phases in the
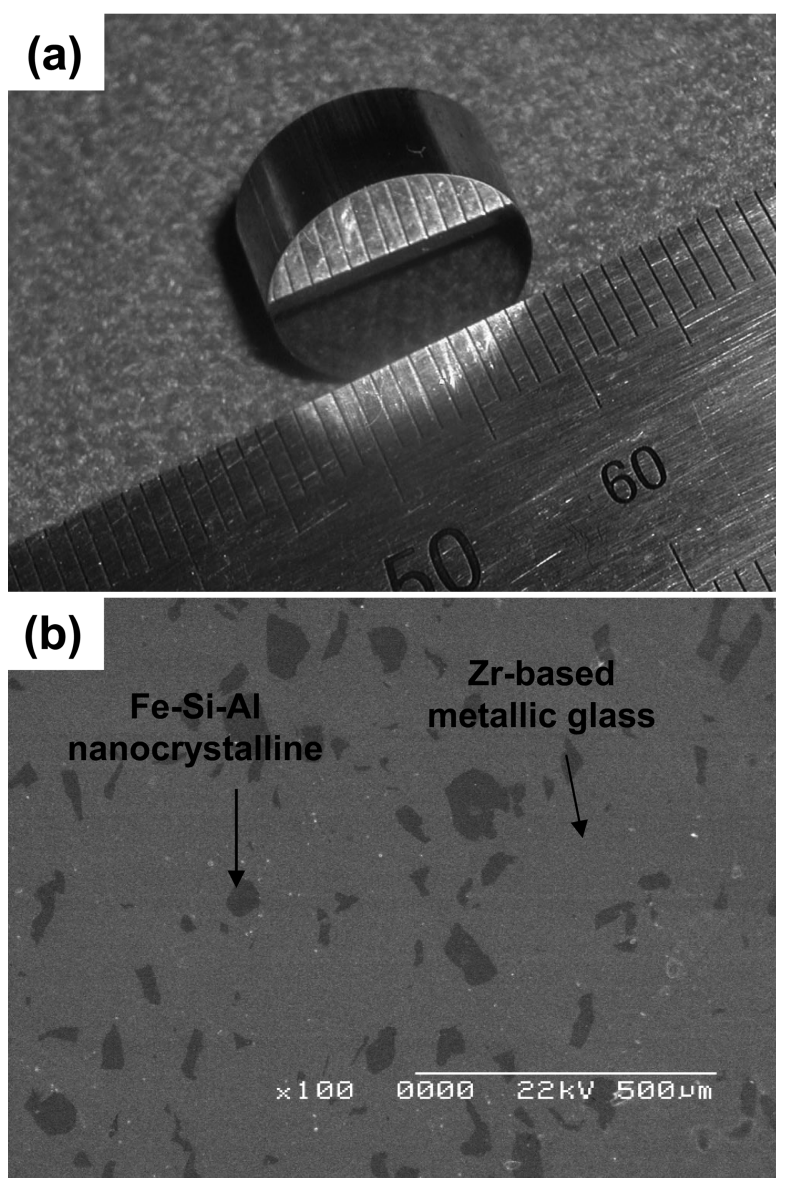

Fig. 3. (a) The typical appearance and (b) the SEM morphology of the polished cross section obtained from the consolidated $\mathrm{Zr}_{62} \mathrm{Al}_{8} \mathrm{Ni}_{13} \mathrm{Cu}_{17}$ containing $20 \mathrm{Vol} \%$ Fe-based nano-structured powders. supercooled liquid region, resulting in a full densification. Fig. 4 shows the typical XRD patterns and DSC curves obtained from the consolidated samples of the monolithic BMGs and the MGMCs containing 20 Vol.\% Fe-based nano-structured powders. The monolithic BMGs showed
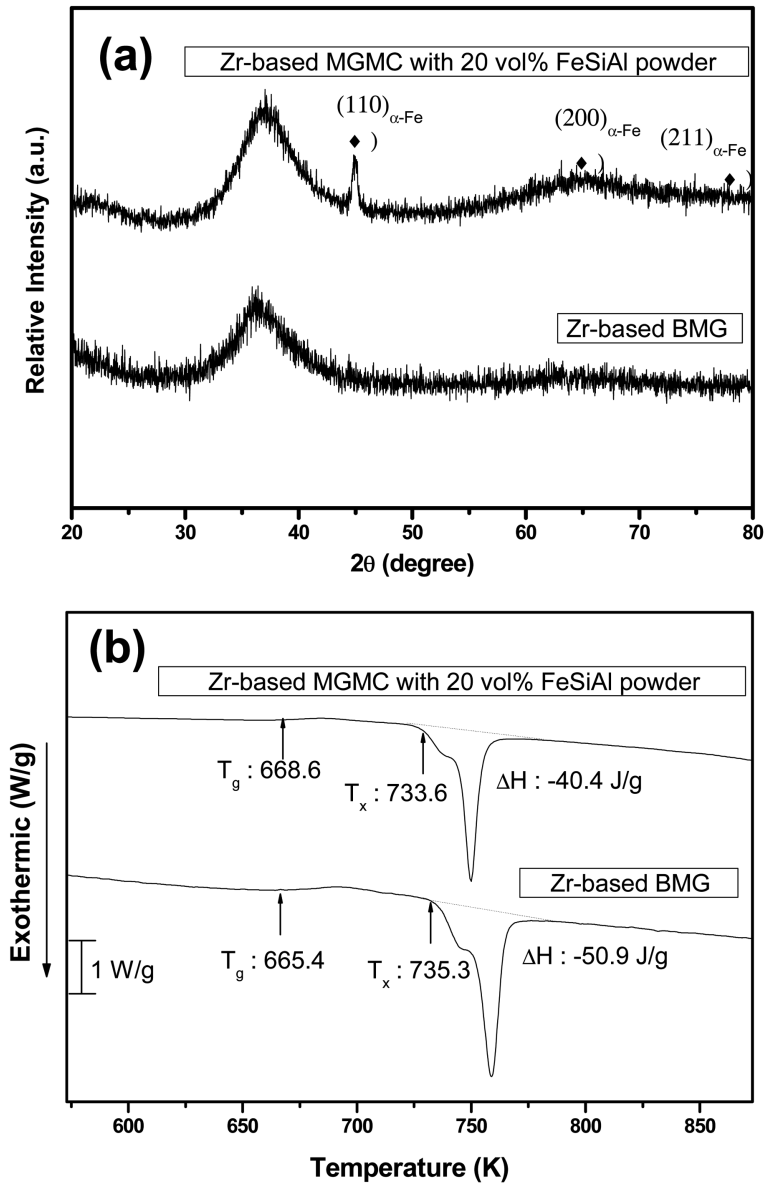

Fig. 4. (a) XRD patterns and (b) DSC curves obtained from the consolidated samples of the monolithic BMGs and the MGMCs containing $20 \mathrm{Vol} \% \mathrm{Fe}$-based nano-structured powders. 


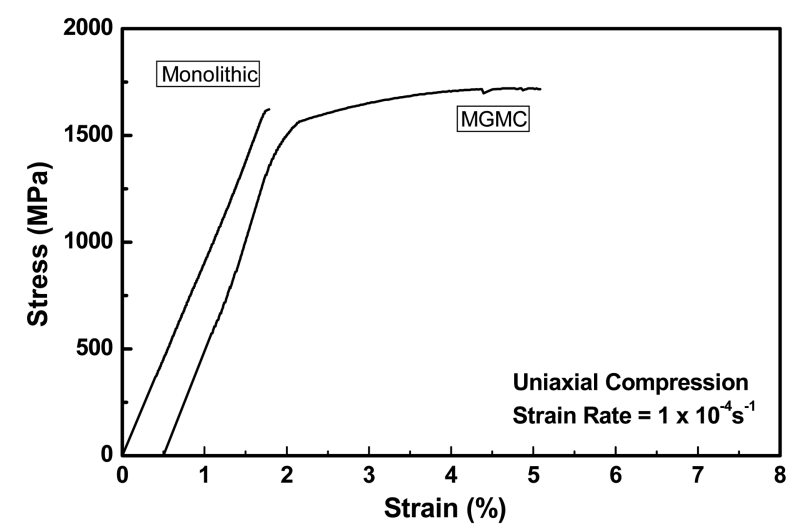

Fig. 5. Stress-strain curves of the monolithic BMG and MGMCs.

Table 1. Mechanical properties of the monolithic BMG and MGMCs.

\begin{tabular}{cccc}
\hline Sample & $\begin{array}{c}\text { Strength } \\
(\mathrm{MPa})\end{array}$ & $\begin{array}{c}\text { Total strain } \\
(\%)\end{array}$ & $\begin{array}{c}\text { Plastic strain } \\
(\%)\end{array}$ \\
\hline Monolithic & 1623 & 1.8 & $\sim 0$ \\
Composite & 1726 & 4.3 & 2.5 \\
\hline
\end{tabular}

a broad halo peak in the $2 \theta$ range of $35-47^{\circ}$, characteristic of an amorphous structure, while the MGMCs showed sharp peaks diffracted from the $\alpha$-Fe superimposed on a halo pattern, indicating that the MGMC consists of the crystalline Fe-based powder and the matrix of a fully amorphous phased. From the DSC traces, the monolithic $\mathrm{Zr}_{62} \mathrm{Al}_{8} \mathrm{Ni}_{13} \mathrm{Cu}_{17}$ BMG had the glass transition temperature $\left(\mathrm{T}_{\mathrm{g}}\right)$ of $665.4 \mathrm{~K}$, the onset temperature of crystallization $\left(\mathrm{T}_{\mathrm{x}}\right)$ of $735.3 \mathrm{~K}$ and the integrated heat of crystallization of $50.9 \mathrm{~J} / \mathrm{g}$. These values are almost similar to those of the metallic glass powders, indicating that no devitrification occurred during SPS process. Note that, the $\Delta \mathrm{H}$ of the MGMC containing $20 \mathrm{Vol} \%$ Fe-based nano-structured powders was around $80 \%$ of that of monolithic $\mathrm{BMG}$, again confirming that no devitrification occurred in the MGMC samples during consolidation. The XRD and DSC results indicate that the matrix of the monolithic BMGs and MGMCs remains as a fully amorphous phase after consolidation process.

Fig. 5 shows the stress-strain curves of the monolithic BMG and MGMC samples tested under the uniaxial compressive condition at room temperature. The results of the compression tests are summarized in Table 1. The monolithic $\mathrm{Zr}_{62} \mathrm{Al}_{8} \mathrm{Ni}_{13} \mathrm{Cu}_{17} \mathrm{BMG}$ samples exhibited fracture strength of about $1.62 \mathrm{GPa}$ similar to that of as-cast samples $(\sim 1.7 \mathrm{GPa})$, which can be attributed to the good bonding characteristics between the metallic glass powders. However, no plastic deformation region was observed, possibly due to the occurrence of structural relaxation in the amorphous structure during SPS process. This stressstrain behavior has been commonly observed in the monolithic BMGs consolidated from metallic glass powders. ${ }^{7,8)}$ The MGMC shows some macroscopic plasticity after yielding and the higher strength level than that of monolithic BMG. The fracture strength and total strain of the $\mathrm{Zr}_{62} \mathrm{Al}_{8} \mathrm{Ni}_{13} \mathrm{Cu}_{17}$ MGMC containing $20 \mathrm{Vol} . \%$ Fe-based nano-structured powders were $1726 \mathrm{MPa}$ and $4.3 \%$, respectively.

In order to know the effect of introducing Fe-based nano-structured powders in the metallic glass matrix on the fracture, the fracture surface of the failed MGMC sample was observed using a scanning electron microscope. Fig. 6 shows the fracture surface of failed $\mathrm{Zr}_{62} \mathrm{Al}_{8} \mathrm{Ni}_{13} \mathrm{Cu}_{17}$ MGMC sample containing $20 \mathrm{Vol} \% \%$ Fe-based nano-structured powders. As seen in Fig. 6, the compressive fracture takes place along the maximum shear plane, which is declined by about $43^{\circ}$ to the direction of compressive load and a

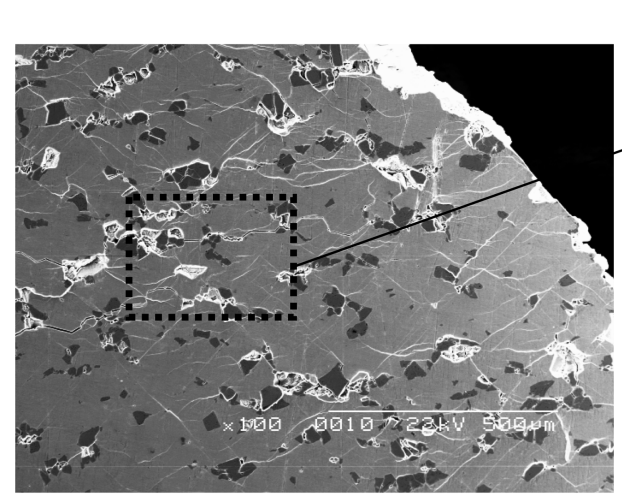

(a)

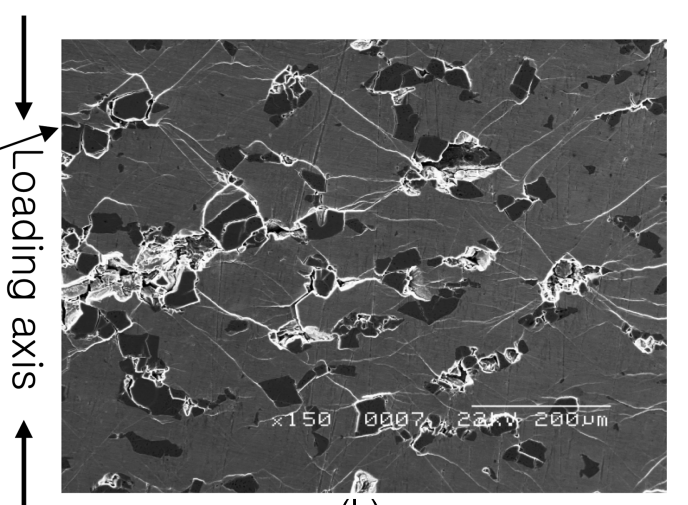

(b)

Fig. 6. (a) Scanning electron micrograph of compressive fracture surface of failed Zr62A18Ni13Cu17 MGMC containing 20 vol \% Febased nano-structured powders. (b) magnified view of (a). 
large number of the shear bands developed at the surface of the specimen, reflecting the significantly improved plastic strain in the BMG matrix composite.

The spark plasma sintering (SPS) process, which is a technique developed for rapid sintering of metals, ceramics and composite materials, has a great potential for producing specimens without crystallization of metallic glasses in a short sintering time. In this study, the Zr-based bulk metallic glass matrix composite was successfully fabricated by spark plasma sintering of a mixture of gas-atomized metallic glass powders and Fe-based nano-structured powders. As shown in Fig. 5, the catastrophic failure can be avoided by introducing a nano-structured particle in the metallic glass matrix. Previously, it has been reported that the enhanced plasticity of the extruded MGMC results from the formation of multiple shear bands initiated from the interface between the second ductile phase and metallic glass matrix., ${ }^{4,5)}$

The nature of the interface is one of the factors determining mechanical properties of the composite materials. The high interfacial strength between the reinforcement and amorphous matrix can effectively prevent the shear band propagation without crack initiation, and can act as a source generating multiple shear bands. Most BMG matrix composites reinforced by ductile metals, refractory metals, and ceramic particles were developed to overcome the lack of plasticity of the BMG matrix. In conventional BMG matrix composites, the role of the reinforcement

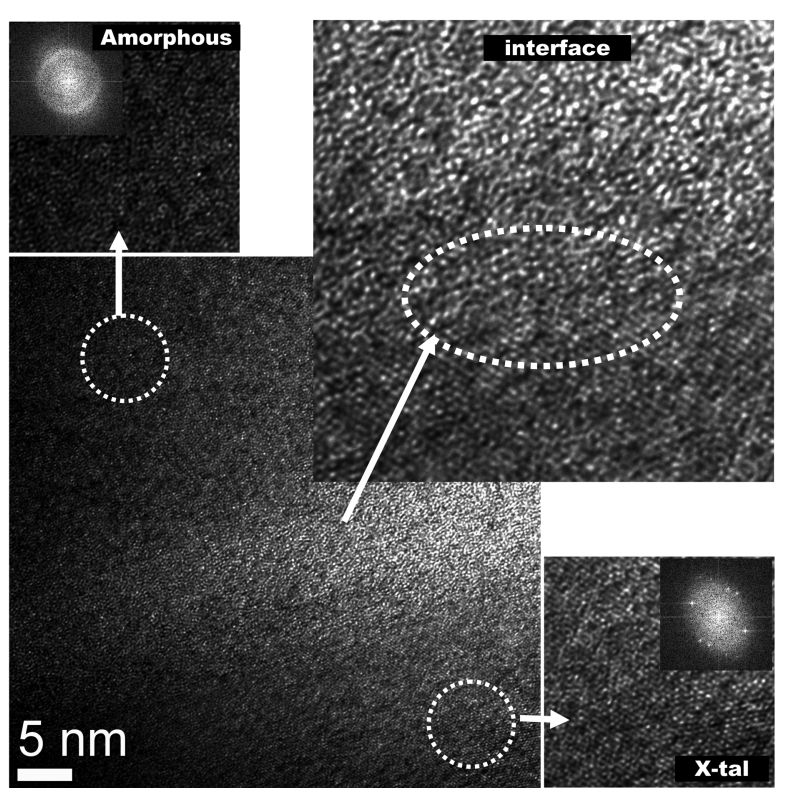

Fig. 7. High resolution TEM images of interface between the metallic glass powder and nano-structured powder. metal phase in the metallic glass matrix composite is to initiate many shear bands at the glass-particle interface and hinder the propagation of shear bands through the metallic glass matrix, for example, by absorbing shear strain and thereby enhancing the total plasticity of the composites. Kim et al. reported that simultaneous improvement of strength and ductility can be obtained by precipitation of nanoquasicrystal in the amorphous matrix due to the structural similarity between quasicrystalline and amorphous phase. ${ }^{7}$

The high resolution TEM images shown in Fig. 7 show the typical microstructure of interface between the metallic glass powder and nano-structured powder. The high resolution image showing the atomic structure of the interface in consolidated BMGC (Fig. 7) clearly indicates a gradual structural change from the nanocrystalline to amorphous structure at the interface. These results indicate that nanostructured particle can be effectively served to improve the mechanical properties. The good interface between amorphous phase and nanocrystalline phase may contribute to the increase of yield strength. Therefore, the high strength of the consolidated BMGC is considered to be due to the good interparticle bonding between the metallic glass and nano-structured powders. Unlike other amorphous matrix composites, in which improved ductility could be obtained at the expense of their strength, the developed composite exhibited significant improvement both in strength and ductility. An investigation on the effect of volume fraction of nano-structured powders on the mechanical properties is underway.

\section{Conclusion}

The $\mathrm{Zr}_{62} \mathrm{Al}_{8} \mathrm{Ni}_{13} \mathrm{Cu}_{17}$ MGMC reinforced by Fe-based nano-structured powder has been successfully synthesized by spark plasma sintering of gas atomized metallic glass powders at the supercooled liquid state. Full densification of MGMCs was achieved by the viscous flow of the metallic glass powders in the supercooled liquid region during consolidation process. The MGMCs samples show some macroscopic plasticity after yielding, which is related to the formation of multiple shear bands and confinement of propagation of shear bands. Unlike other amorphous matrix composites, in which improved ductility could be obtained at the expense of their strength, the developed composite exhibited significant improvement both in strength and ductility. 


\section{Acknowledgements}

This research was supported by a grant (code \# : 2009K 000353) from the Center for Nanostructured Materials Technology under 21st Century Frontier R\&D programs of the Korean Ministry of Science and Technology, and the Korea Institute of Science and Technology.

\section{References}

1. A. Inoue, Acta. Mater., 48, 279 (2000).

2. H. Chen, Y. He, G. J. Shiftlet and S .J. Poon, Nature, 367, 541 (1994).

3. A. L. Greer, Science, 267, 1947 (1995).

4. R. D. Conner, R. B. Dandliker and W. L. Johnson, Acta Mater., 46, 6089 (1998).

5. C. M. Lee, K. W. Park, B. J. Lee, J. H. Shim and J. C. Lee, Kor. J. Mater. Res., 19, 276 (2009).

6. J. C. Lee, Y. C. Kim, J. P. Ahn and H. S. Kim, Acta Meter., 53, 129 (2004).

7. Y. C. Kim, J. H. Na, J. M. Park, D. H. Kim, J. K. Lee and W. T. Kim, Appl. Phys. Lett., 83, 3093 (2003).

8. R. D. Conner, R. B. Dandliker and W. L. Johnson, Acta Mater., 46, 6089 (1998).

9. C. C. Hays, C. P. Kim and W. L. Johnson, Phys. Rev.
Lett., 84, 2901 (2000).

10. J. Eckert, M. Seidel, A. Kubler, R. Klement and L. Schultz, Scripta Metall., 38, 595 (1998).

11. D. H. Bae, M. H. Lee, D. H. Kim and D. J. Sordelet, Appl. Phys. Lett., 83, 2312 (2003).

12. H. Choi-Yim, R. Busch, U. Köster and W. L. Johnson, Acta Mater., 47, 2455 (1999).

13. Y. Kawamura, H. kato, A. Inoue and T. Masumoto, Appl. Phys. Lett., 67, 2008 (1995).

14. M. H. Lee, D. H. Bae, W. T. Kim, D. H. Kim, E. Rozhkova, P. B. Wheelock and D. J. Sordelet, J. NonCryst Solids, 315, 89 (2003).

15. H. J. Kim, J. K. Lee, S. Y. Shin, H. G. Jeong, D. H. Kim and J. C. Bae, Intermetallics, 12, 1109 (2004).

16. G. M. Dougherty, G. J. Shiftlet and S. J. Poon, Acta Metall. Mater., 42, 2275 (1994).

17. Y. Kawamura, H. Kato, A. Inoue and T. Masumoto, Appl. Phys. Lett., 67, 2008 (1995).

18. L. L. Ye, Z. G. Liu, K. Raviprasad, M. X. Quan, M. Umemoto and Z. Q. Hu, Mater. Sci. Eng. A, 241, 290 (1998).

19. D. J. Sordelet, E. Rozhkova, M. F. Besser and M. J. Kramer, J. Non-Cryst. Solids, 317, 137 (2003).

20. J. Robertson, J. T. Im, I. Karaman, K. T. Hartwig and I. E. Anderson, J. Non-Cryst. Solids, 317, 144 (2003).

21. K. Ozaki, T. Nishio, A. Matsumoto and K. Kobayashi, Mater. Sci. Eng. A, 375, 857 (2004).

22. M. Tokita, J. Soc. Powder Technol. Jpn., 30, 790 (1995). 